galactopoietic response ${ }^{13}$ and contains $30-50 \mathrm{mgm}$. of growth hormone?. The results show that the galactopoietic activity of $30 \mathrm{mgm}$. of growth hormone is probably greater than that of $5 \mathrm{ml}$. of our crude ox anterior pituitary extract and little different from that of $10 \mathrm{ml}$. Thus, in these short-term experiments, the whole of the galactopoietic activity of the crude extract may well be accredited to the growth hormone it contains. No positive galactopoietic effect of prolactin or of adrenocorticotropin was observed with the doses we employed, nor was the simultaneous administration of these hormones with growth hormone found to influence significantly the galactopoietic activity of the latter (see table). In long-term experiments, involving repeated injections of crude extract (for example, over a period of three weeks $\mathbf{3}, 18$ ), pituitary thyrotropin might play a part, since the galactopoietic action of the thyroid hormone is well attested (see Bailey et al. ${ }^{14}$ ). In such experiments of longer duration, it is possible that the galactopoietic action of the crude extract might be greater than could be attributed to the growth hormone it contained; but this is a matter for further investigation.

The table shows that $60 \mathrm{mgm}$. of growth hormone has no greater galactopoietic effect than has $30 \mathrm{mgm}$., such an observation being in agreement with the previously observed almost maximal galactopoietic effect of $10 \mathrm{ml}$. of our crude extract ${ }^{13}$. Indeed, the effect of $60 \mathrm{mgm}$. of growth hormone is slightly smaller than that of $30 \mathrm{mgm}$. (though the difference is not statistically significant on the basis of our results), and if this possible difference is real we are at present unable to account for it.

The administration of $28 \mathrm{mgm}$. of adrenocorticotropin induced a significant depression of milk yield, and a similar tendency (statistically significant only at Shinfield) was also observed with a dose of $7 \mathrm{mgm}$. of this hormone. On the other hand, Dr. A. Roy, in earlier experiments in our laboratories, found that under some conditions adrenocorticotropin could exert a substantial galactopoietic action (see Young ${ }^{2}$ ). It is clear that the magnitude of the dose of adrenocorticotropin may be of critical importance in such experiments, and this possibility is under investigation.

We believe the galactopoietic action of growth hormone to be of physiological significance. Treatment with pituitary growth hormone may induce growth (H. M. Evans), the secretion of extra milk (present paper) or diabetes 78 , according to the age, species and condition of the treated animal. The diabetogenic action of growth hormone can be regarded as "the pathological outcome of an excessive stimulation of those processes (depression of oxidation of carbohydrate with enhancement of protein storage and of fat combustion) which, under more physio. logical conditions, lead to such deposition of new tissue as is associated with growth" (Young" ${ }^{15}$; see also refs. 8, 16). As was pointed out some years ago: "Growth, including foetal growth, and milk production are processes requiring a special type of metabolic control, in that they both necessitate the preservation from oxidation of foodstuff that would otherwise, in an animal in equilibrium, be oxidized. ... Since growth, galactopoiesis and diabetogenesis all involve a restraint on oxidative processes, it would not be surprising if there were some relation. ship between the hormonal mechanisms concerned with the control of these phenomena" (Young 2 ). Our demonstration of the galactopoietic activity of growth hormone, already known to be diabetogenic under some conditions, satisfactorily conforms with the expected concinnity of physiological pattern.

We are indebted to Dr. D. P. Cuthbertson, director of the Rowett Research Institute, Aberdeenshire, for permission to use the herds at this Institute; to Mr. A. S. Foot for co-operation in making the cows at Shinfield available to us; and to Mr. C. P. Cox for assistance with the statistical analysis of the data. We also gratefully acknowledge the tenure of a Medical Research Council Training Studentship by P. M. Cotes, and the assistance given by the Medical Research Council towards the cost of this work by an expense grant to F. G. Young.

'Folley, S. J. (1945), in "Marshall's Physiology of Reproduction" (third edit., ed. A. S. Parkes), Chap. 20 (in the press)

2 Young, F. G., Brit. Med. Bull., 5, 155 (1947).

${ }^{3}$ Folley, S. J., and Young, F, G., J. Endocrinol., 2, 226 (1940).

4 Bergman, A. J., and Turner, C. W., J. Dairy Sci., 23, 1229 (1940).

${ }^{5}$ Asimov, G. J., and Krouze, N. K., J. Dairy Sci., 20, 289 (1937).

- Folley, S. J., and Young, F. G., Proc. Roy. Soc., B, 126, 45 (1938)

${ }^{7}$ Cotes, P. M., Reid, E., and Young, F. G., Nature, 164, 209 (1949).

${ }^{8}$ Milman, A. E., and Russel, J. A., Fed. Proc., 8, 111 (1949).

- Wilhelmi, A. E., Fishman, J. B., and Russell, J. A., J. Bial. Chem. 176,735 (1948).

${ }^{10} \mathrm{Li}$, C. H., Evans, H. M., and Simpson, M. E., J. Biol. Chem., 149, 413 (1943).

${ }^{11} \mathrm{Li}$, C. H., Simpson, M. E., and Evans, H. M., J. Biol. Chem., 146, 627 (1942).

12 Young, F. G., Brit. Med. J.. 2, 897 (1941).

13 Folley, S. J., and Young, F. G., J. Endocrinol, 4, 194 (1945).

${ }^{14}$ Bailey, G. L., Bartlett, S., and Folley, S. J., Nature, 163, 800 (1949),

is Young, F. G., Biochem. J., 39, 515 (1945).

${ }^{18}$ Gaarenstroom, J. H., Hublé, J., and de Jongh, S. E., J. Endocrinol. 6, $71(1949)$.

\section{RADIATION EFFECTS DUE TO PHOSPHORUS-32 IN FERTILIZER EXPERIMENTS}

\author{
By R. SCOTT RUSSELL, S. N. ADAMS \\ AND \\ P. MARTIN \\ Department of Agriculture, University of Oxford
}

T has boon shown in water culture ${ }^{1}$ that the rate of phosphorus absorption by plants is, under certaid conditions, significantly reduced when activitieg of phosphorus-32 as low as 10 microcuries per line are used as a tracer. Root-growth is also depressed; nevertheless, the development of the aerial parts of plants provides no consistent index of radiation damage. These effects are explained by the metabolic accumulation of labelled phosphorus, which may cause the root tips of rapidly absorbing plants to be exposed to radiation many hundred times more intense than that in the culture solution.

Efiects resulting from the addition of labelled fertilizers to the soil are now being investigated. Plants are grown in pots containing 1,500 gm. soil, to which a constant level of potassium dihydrogen phosphate, labelled with varying activities of phos. phorus-32, is added in solution. The full results will be described in due course in the Journal of Experi. mental Botany. This report is made since, despite the preliminary nature of the present results, they indicate that the seriousness of radiation damage in fertilizer experiments can be considerably greater than has frequently been supposed. The interpretation of radiation effects due to tracers in the soil is more complex than in water culture, since naturallyoccurring soil phosphates are always present, and 
Table 1. Effect of varying activities of phosphorus-s2 on growth of barley, All treatments received the equivalent of $8 \mathrm{lb}$. total phosphorus/acre.

\begin{tabular}{|c|c|c|c|c|c|}
\hline $\begin{array}{l}\text { Treatment: } \\
\qquad \begin{array}{l}\mu \mathrm{C} . \mathrm{P}^{s 2} / \text { culture pot } \\
\mu \mathrm{C} . \mathrm{P}^{32} / \mathrm{gm} . \mathrm{P}\end{array}\end{array}$ & $\begin{array}{l}0 \\
0\end{array}$ & ${ }_{18}^{0 \cdot 16}$ & $9^{0 \cdot 8}$ & $460^{4 \cdot 0}$ & L.S.D. \\
\hline $\begin{array}{l}\text { Dry weight (gm./pot) } \\
\text { Shoots } \\
\text { Roots } \\
\text { Fertilizer phosphate absorbed } \\
\text { (gm./pot) } \\
\text { Fertilizer phosphate absorbed } \% \\
\text { Soil phosphate absorbed }\end{array}$ & $\begin{array}{l}2 \cdot 38 \\
1 \cdot 23\end{array}$ & $\begin{array}{r}2 \cdot 46 \\
1 \cdot 22 \\
3 \cdot 42 \\
16 \cdot 74\end{array}$ & $\begin{array}{r}2 \cdot 51 \\
1 \cdot 26 \\
2 \cdot 75 \\
12 \cdot 4\end{array}$ & $\begin{array}{l}2 \cdot 63 \\
1 \cdot 17 \\
2 \cdot 45 \\
7 \cdot 9\end{array}$ & $\begin{array}{c}- \\
0.79(5 \%) \\
(\text { see below) }\end{array}$ \\
\hline $\log _{6} \frac{\text { Fertilizer phosphate absorbed }}{\text { Soll phosphate absorbed }} \%$ & & $2 \cdot 81$ & $2 \cdot 50$ & $2 \cdot 00$ & $\begin{array}{l}0.25(5 \%) \\
0.37(1 \%)\end{array}$ \\
\hline
\end{tabular}

Signiflcant effects in heavy type. Capacity of culture pots, 1,500 gm. soil.

moreover the fertilizer phosphate is largely retained in the upper layers of soil even when it is added in dilute solution. The procedure here used resulted in 97-99 per cent of the fertilizer being retained in the upper two inches of soil. Between experiments, variations due to rainfall occur within these limits. If radiation from the tracer reduces the rate of nutrient absorption, it is apparent that this effect will occur mainly in the roots absorbing from the upper layers of soil. Roots absorbing soil phosphate in the lower horizons will be relatively unaffected. Thus radiation damage should result in an alteration in the proportion of fertilizer to soil phosphorus absorbed.

Table 1 shows the effects in spring-sown barley plants of the equivalent of $8 \mathrm{lb}$. phosphorus per acre, labelled with varying amounts of tracer. Four plants were grown per pot. Neither shoot- nor root-weight is significantly affected, though there is an upward trend in shoots. Phosphorus absorption is, however, depressed when 4 microcuries are applied per pot. When the fertilizer phosphate absorbed is expressed as a percentage of the soil phosphate absorbed, the effect is highly significant in the 4.0 microcuries per pot treatment, and in the 0.8 microcurie treatment it just attains the 5 per cent probability limit. On account of the magnitude of the differences between treatments, natural logarithms have been used for statistical analysis. It may be noted that levels of tracer above $4 \cdot 0$ microcuries have caused no significant increase in the observed effects.

It is apparent that the decay of phosphorus-32 during an experiment will lead to a progressive reduction in the level of radiation. Thus possible effects of recovery from radiation damage merit consideration, especially if the experimental plants remain in an active vegetative state for a considerable period, and if the supply of fertilizer phosphate is not limiting. Both these conditions were satisfied in an experiment on winter wheat grown under cool conditions. Results for a harvest 70 days after the application of fertilizer are given in Table 2. The tracer had then decayed to 3.4 per cent of its original activity. Dry weights again show no significant radiation effects, but the percentage of the absorbed phosphate which came from the fertilizer is increased. Roots show the effect to a markedly less degree than shoots, in which the effect is highly significant when 5 microcuries were added per pot. The suggestion that this is due to root regeneration in the upper layers of the soil is supported by counting the numbers of adventitious roots developed from the stem bases which did not penetrate more than 2 in. below the soil surface. Data on this point are insufficient to be of critical value.

In Table 3 the activities of phosphorus-32 used in a number of fertilizer investigations have been recalculated on the same basis as the present data. Differences not only in method of expressing results but also in the microcurie standard necessarily make these calculations approximate only. Furthermore, difficulties arise in comparing pot and field experiments, though there are reasons for believing that the radiation hazard is of the same order in both types of work ${ }^{8}$. It is none the less apparent that very varying activities of phosphorus-32 have been employed in fertilizer investigations, and that in some instances they have greatly exceeded the levels at which significant effects were observed in the present work. Since radiation damage is dependent on metabolic accumulation, considerable differences are to be expected between experiments. Thus the present results can provide no information applicable

Table 2. Fffect of varying activities of phosphorus-32 on growth of winter wheat. All treatments received the equivalent of 49 lb. total phos. phorus/acre. Harvested 70 days after treatment

\begin{tabular}{|c|c|c|c|c|c|c|}
\hline $\begin{array}{l}\text { Treatment: } \\
\qquad \begin{array}{l}\mu \mathrm{C} . \mathrm{P}^{32} / \text { culture pot } \\
\mu \mathrm{C} . \mathrm{P}^{31} / \mathrm{gm} . \mathrm{P}\end{array}\end{array}$ & $\begin{array}{l}\mathbf{0} \\
\mathbf{0}\end{array}$ & $\begin{array}{r}2 \\
40\end{array}$ & $\begin{array}{r}5 \\
100\end{array}$ & $\begin{array}{r}15 \\
300\end{array}$ & $\begin{array}{l}24^{*} \\
480\end{array}$ & L.S.D. \\
\hline $\begin{array}{l}\text { Dry weight (gm./pot) } \\
\text { Shoots } \\
\text { Roots } \\
\text { Fertilizer phosphate absorbed } \% \\
\begin{array}{l}\text { Soil phosphate absorbed } \\
\text { Shoots } \\
\text { Roots }\end{array}\end{array}$ & $\begin{array}{c}1 \cdot 75 \\
0 \cdot 64 \\
= \\
=\end{array}$ & $\begin{array}{r}1 \cdot 82 \\
0 \cdot 63 \\
\\
89 \\
100\end{array}$ & $\begin{array}{r}1 \cdot 62 \\
0 \cdot 58 \\
\\
110 \\
97\end{array}$ & $\begin{array}{l}1 \cdot 65 \\
0 \cdot 54 \\
215 \\
115 \\
\end{array}$ & $\begin{array}{l}1 \cdot 54 \\
7 \cdot 59 \\
\\
367 \\
123 \\
\end{array}$ & $\begin{array}{c}\square \\
\text { (see below) } \\
-\end{array}$ \\
\hline $\log _{e} \frac{\text { Fertilizer phosphate absorbed }}{\text { Soil phosphate absorbed }} \%$ & - & $4 \cdot 52$ & $5 \cdot 75$ & $5 \cdot 41$ & & $\begin{array}{ll}0.13 & (5 \%) \\
0.21 & (1 \%)\end{array}$ \\
\hline $\begin{array}{l}\text { Number of adventitious roots per pot } \\
\text { which did not penetrate more than } \\
2 \text { in. below soil surface* }\end{array}$ & 8 & 10 & 15 & 21 & 23 & \\
\hline
\end{tabular}

Significant effects in heavy type. * Excluded from statistical analyses on account of insufficient replication. 
to other experimental conditions. It is apparent, however, that radiation effects can invalidate the results of fertilizer experiments when comparatively low activities of tracer are employed. Moreover, the absence of weight changes in shoots does not necessarily indicate that significant radiation effects have not occurred. Thus the assumption that radiation from the tracer has not invalidated experimental results can be fully justified only if it has been shown that the rates of absorption of fertilizer-and soilphosphorus are unchanged when different activities of tracer are used to label a constant quantity of fertilizer phosphorus. No evidence on this question is contained in the papers cited in Table 3.

Table 3. Approximate levels of phosphorus-32 used in fertilizer studies

\begin{tabular}{|c|c|c|c|}
\hline & lb. P/acre & $\begin{array}{l}\mu \mathrm{C} . \mathrm{P}^{32} \\
\text { per } \mathrm{gm}_{\mathbf{P}}\end{array}$ & $\begin{array}{c}\mu \text { C. Pas per } \\
\text { pot }(1,500 \\
\text { gm. soil) }\end{array}$ \\
\hline $\begin{array}{l}\text { Hendricks and Dean (ref. 2) } \\
\text { Dean et al. (ref. 3) } \\
\text { Spjnks and Barber (ref. 4) } \\
\text { Spinks and Barber (ref. 5) } \\
\text { Spinks et al. (ref. 6) } \\
\text { Dion et al. (ref. 7) }\end{array}$ & $\begin{array}{c}100 \\
6 \cdot 7 \\
6 \cdot 7 \\
6 \cdot 7-60 \\
5-21\end{array}$ & $\begin{array}{c}\overrightarrow{43-215} \\
150-1,000 \\
54 \\
33-1600 \\
26-260\end{array}$ & $\begin{array}{c}38-938 \\
\overline{0} \\
0 \cdot 5 \\
0.14 \\
\longrightarrow\end{array}$ \\
\hline
\end{tabular}

Data converted from published results, assuming, where necessary, that $5.5 \times 10^{5}$ counts/min. correspond to 1 microcurie.

Spinks and his co-workers ${ }^{7}$ have recently given some consideration to radiation effects. Their conclusion, that radiation effects have not occurred in their experiments, is, however, based entirely on the assumed absence of weight changes in the shoots of plants treated with labelled phosphorus. It is to be noted that the greater part of the data is for plants treated with 26 microcuries of phosphorus-32 per gm. of total phosphorus, a considerably lower level than that usually used in their earlier work (see Table 3). Yet in one series of their results (7, Table a) plants treated with tracer showed significantly increased shoot-weights. They attribute this to uneven germination on one of their two experimental sites; but this can scarcely explain why, in both sites, the treatment which caused the greatest phosphorus absorption (namely, $\mathrm{NH}_{4} \mathrm{H}_{2} \mathrm{PO}_{4}, 48 \mathrm{lb}$./acre) showed the greatest increase in shoot-weight. There are some indications in the results of both the water culture investigation $s^{1}$ and the present work that the absorption of radioactive phosphorus may, under certain conditions, result in increased shoot-weight. These trends are possibly explained by downward translocation being depressed on account of reduced root activity. It is not suggested that the data of Spinks and his associates can be interpreted only in this way. However, results which indicate this possibility are unconvincing as evidence that no radiation damage has occurred.

We acknowledge with thanks the generous financial aid of the Agricultural Research Council, which has enabled us to undertake this work. We are also much indebted to Prof. G. E. Blackman for, his encouragement and suggestions during the course of the work.

1 Russell, R. S., and Martin, R. P., Nature, 163, 71 (1949).

"Hendricks. S. B., and Dean, L. A., Soil Sci. Soc. Amer. P oc., 12, 98 (1948).

'Dean, L. A., Nelson, W. I., MacKenzie, A. J., Armiger, W. H., and Hill, W L., Soil'Sci. Soc. Amer. Proc., 12, 107 (1948).

- Spinks, J. W. T., and Barber, S. A., Sci. Agric., 27, 145 (1947).

${ }^{5}$ Spinks, J. W. T., and Barber, S. A., Sci. Agric., 28, 79 (1948).

- Spinks, J. W. T., Dion, H. G., Reade, M., and Dehm, J. E., Sci. Agric., 28, 309 (1948).

7 Dion, G., Bedford, C. F., St. Arnaud, R. J., and Spinks, J. W. T., Nature, 163, 907 (1949).

${ }^{2}$ Russell, R. S., J. Chem. Soc. (in the press).

\section{MEETING OF BAVARIAN PHYSICISTS $\quad 13 / 2$}

$\mathrm{T}$ HE first post-war megthng of Bavarian physicists, held in Munich offing July 29-August 2, was attended by aluost noted physicists of the western zones of Germuny and even by one representative of the easternisectod of Berlin. It was a happy occasion, connected forth a series of celebrations in honour of the pixtisth birthday of Walther Gerlach, who has recendy been re-elected Rector Magnificus of the University of Munich. Gerlach's gay spirit indirectly enlivened all activities, and the dull solemnity of the usual congress dinners was expelled by a cabaret staged by his pupils.

Of more than forty scientific addresses, the following aroused the greatest interest, the order being that in which they were delivered. E. Smits and W. Gentner (Freiburg im Breisgau) described their determination of the argon content in sylvine (potassium chloride) of different ages-200 to $35 \times 10^{6}$ years old. They found, in agreement with Aldrich and Nier (Phys. Rev., 1948), a ratio of $K$-capture to beta-radioactivity of $5-10$ per cent. R. Fleischmann (Hamburg) presented a procedure for measuring the absolute phase difference in the reflexion of light. $\mathrm{He}$ has succeeded in determining the refractive index and the absorption coefficient in a manner different from, and simpler than, that of Drude. A. Kochendoerfer (Stuttgart) stated that Mott and Nabarro's theory describes a kind of hardening which is different from that with which he is concerned; in his work the hardening occurs alone when pure crystals are sheared and hence must be due to the gliding as such. M. Schuler (Göttingen) has observed that clock pendulums made of invar may change their length spontaneously, becoming either shorter or longer.

When intense X-ray flashes of $10^{-7}$ sec. duration are shot through electric sparks in liquids, in a direction parallel to the spark path, it has been found by $W$ Schaaffs (Berlin-Siemensstadt) that short sound-wave pulses with a velocity of $10,000 \mathrm{~m}$. per sec. are emitted, and matter is compressed to three times its normal density. K. H. Hellwege (Gottin. gen, has carried on Bethe's work with special application to the bi-axial crystals of the rare earths. H. A. Bomke (Munich) described how, by combining a micro-ionization chamber with an extremely sensitive amplifier arrangement, he can determine local deviations in a three-dimensional radium or X-ray field; this is of medical importance. W. Groth (Hamburg) has found new possibilities for the separation of isotopes by diffusion in the gas phase. H. Auer (Munich) discussed some physical problems of age hardening in aluminium-copper alloys. $\mathrm{E}$ Kappler (Münster) defined a physical scale of hardness; starting from Hertz's elastic formulæ, he developed a theory of plasticity.

Ferromagnetic remanence in normal polycrystalline materials was dealt with by Walter Gerlach. An inner demagnetizing factor is found experimentally to rise near the Curie point, indicating that the ferromagnetism of different domains within one specimen disappears at different temperatures. The result is that the true remanence remains constant at about half saturation over a large range of temperatures and vanishes gradually immediately below the Curie point. The coercive force has a sharp maximum at the same temperature. H. Schroeder (Munich) 